\title{
PENERAPAN KINERJA DENGAN PENDEKATAN BALANCED SCORECARD PADA PT POS INDONESIA CABANG KUTACANE
}

\author{
Desi Aramana \\ Prodi Akuntansi Universitas Gunung Leuser Kutacane \\ desiaramana@gmail.com
}

\begin{abstract}
The purpose of this study was to determine how the application of financial performance with the balanced scorecard approach at PT Pos Indonesia Kutacane. This research uses descriptive methods with qualitative data and quantitative data. Data analysis techniques were performed using validity and reliability tests, by looking at fact data from the company based on each perspective-perspective contained in the belenced scorecard, namely: financial perspective, customer perspective, internal business process perspective, and growth perspective and learning. The results of the study at PT Pos Indonesia Kutacane Branch showed that financial performance showed poor conditions in the period 2016 to 2018 as measured by the ratio used, the performance of the customer perspective had done various things to provide good service to customers, the performance of the process perspective Internal business which includes innovation and observation of employees shows good results, and performance on the growth perspective and lessons from observations of employee capability and employee satisfaction show good results.
\end{abstract}

Keywords: application of company performance, Balanced Scorecard

\section{PENDAHULUAN}

Pos Indonesia merupakan sebuah badan usaha milik Negara (BUMN) Indonesia yang bergerak dilayanan pos. Berdiri pada tahun 1746, saham pos Indonesia sepenuhnya dimiliki pemerintah Indonesia. Saat ini pos Indonesia tidak hanya melayani jasa pos dan kurir, tetapi juga masalah keuangan, yang didukung oleh titik jaringan sebanyak \pm 4.000 kantor pos dan \pm 28.000 agen pos yang tersebar diseluruh wilayah Indonesia. Dalam melaksanakan pelayanan pos di Indonesia, pos Indonesia membagi wilayah Negara Indonesia sebelas daerah atau divisi regional dalam pengoperasiannya. Pembagian divisi-divisi tersebut mencakup semua provinsi yang ada di Indonesia. Pos Indonesia bagus dalam melayani pelanggannya, baik diskala nasional maupun internasional, tidak terbatas hanya dalam dunia perposan, tetapi juga dalam dunia keuangan. Fasilitas transfer uang melelui pos Indonesia bisa dinikmati oleh para pelanggannya.

Entitas bisnis dewasa ini memerlukan sebuah pengukuran kinerja yang multi perspektif atau pengukuran komprehensif yang dapat mereflesikan kebutuhan masingmasing pemangku kepentingan. Jika perusahaan menerapkan pengukuran kinerja komprehensif, hal ini diharapkan dapat membantu manajemen dalam mengukur sejauh mana tercapainya strategi yang telah ditetapkan perusahaan. Penilaian kinerja yang komprehensif juga sangat diperlukan dengan tujuan untuk melakukan pengelolaan kinerja sehingga membantu mengintegrasikan tujuan perusahaan, individu maupun kelompok kerja.

PT. Pos Indonesia adalah salah satu BUMN yang bergerak dalam bidang jasa pelayanan lalu lintas berita, uang, barang dengan memiliki jaringan pelayanan terbesar dan tersebar di seluruh pelosok tanah air. Keberhasilan dan kelangsungan hidup perusahaan ini sangat tergantung pada sejauh mana para pegawai dapat memberikan pelayanan dalam kualitas yang sesuai dengan harapan dan keinginan para pengguna jasa dan seberapa efektif kinerjanya. Dalam menghadapi tuntutan masyarakat akan peningkatan pelayanan baik kualitas maupun kuantitasnya dan untuk tetap survive maka setiap kantor diusahakan untuk tidak berbuat salah yang menyebabkan keterlambatan pengiriman pos.

Balanced scorecard untuk pertama kali dicetuskan oleh Kaplan dan Norton pada tahun 1997 sebagai salah satu alat pengukuran kinerja pengganti pengukuran kinerja secara tradisional. Balanced scorecard cocok diimplementasikan pada semua jenis entitas bisnis karena semua entitas memerlukan sebuah sistem pengukuran yang mampu menghitung ukuran-ukuran keuangan dan juga non keuangan. Perspektif-perspektif yang dijabarkan dalam balnced scorecard dapat merefleksikan kebutuhan tiap-tiap pemangku kepentingan dan jika balanced scorecard diterapkan pada perusahaan, maka perusahaan bisa mengawasi atau memantau hasil yang didapat perusahaan dalam short term maupun long term, dengan kata lain, balanced scorecard bisa diimplementasikan pada semua organisasi bisnis yang menghasilkan produk maupun yang menghasilkan jasa.

Balanced scorecard yang dirancang dengan baik mengkombinasikan antara pengukuran keuangan dari kinerja masa lalu dengan pengukuran dari pemicu kerja masa depan perusahaan. Balanced scorecard adalah metodologi perangkat evaluasi dengan empat perspektif yang dikembangkan oleh Kaplan and Norton. Balanced scorecard menilai kinerja suatu organisasi atau perusahaan dalam suatu rentang waktu tertentu.

Balanced scorecard ditemukan efektive untuk menggaris bawahi permasalahan yang ada dan mengidentifikasi ruang untuk perbaikkan. Balanced sorecard juga dapat mengungkapkan kontribusi PT pos Indonesia cabang kutacane untuk perbaikan kinerja perusahaan. 


\section{LANDASAN TEORITIS}

Menurut mangkunegara (2016:67) istilah kinerja berasal dari kata job performance atau actual permormanse (prestasi kerja atau prestasi sesungguhnya yang dicapai seseorang). Pengertian kinerja adalah hasil kinerja secara kualitas dan kuantitas yang dicapai oleh seorang pegawai melaksanakan tugasnya sesuai dengan tanggung jawab yang diberikan kepadanya.

Rivai (2015:12) memberikan pengertian bahwa kinerja atau prestasi kerja adalah hasil atau tingkat keberhasilan seseorang secara keseluruhan selama periode tertentu didalam melaksanakan tugas dibandingkan dengan berbagai kemungkinan, seperti standar hasil kerja, target atau sasaran atau kriteria yang telah ditentukan terlebih dahulu dan disepakati bersama.

Berdasarkan beberapa pendapat kinerja dan prestasi kinerja dapat disimpulkan bahwa pengertian kinerja maupun prestasi kinerja mengandung substansi pencapaian hasil kerja oleh seseorang. Dengan demikian bahwa kinerja maupun prestasi kerja merupakan cerminan hasil yang dicapai oleh seseorang atau sekelompok orang. Kinerja perorangan (individual performense) dengan kinerja lembaga (institusional performense) atau kinerja perusahaan (comporate performense) terdapat hubungan yang erat. Dengan perkataan lain bila kinerja karyawan (individual performense) baik maka kemumgkinan beras kinerja perusahaan (comporate performense) juga baik.

\section{Balanced Scorecard}

Balanced scorecard Adalah seperangkat ukuran kinerja kuncinya beriorentasi hasil secara terintegrasi, meliputi ukuran financial dan non financial, yang terdiiri dari kinerja saat ini dari pengendali kinerja masa depan. balanced scorecard seharusnya menjadi sebuah komtemporer dari sistem managemen strategis yang menghubungkan isi entitas nilai utama, dan visi dimasa depan dengan strategi, target, dan prakarsa yang secara eksplisit dirancang untuk menginformasikan dan memotifasi usaha yang berkelanjutan menuju perbaikan, identivikasi, komunikasi, dan evaluasi atas indicator indicator kinerja kunci ini memainkan peranan penting dalam perencanaan strategis menterjemahkan strategi kedalam tindakan, dan dalam pengevaluasian kinerja, (Herry 2016:226).

Balance scorecard dikembangkan oleh Drs. Robert Kaplan (di havard bussines School) and david norton pada awal tahun 1990. Balanced scorecard terdiri dari 2 kata yaitu Balanced (berimbang) diartikan juga sebagai keseimbangan antara penilaian keuangan dan non keuangan, peniaian pada jangka waktu baik jangka pendek dan jangka panjang, penilaian internal dan eksternal. Sedangkan scorecard (kartu skor) yaitu kartu untuk mencatat penilaian seseorang (sujarweni, 2015:134). Melalui kartu ini skor yang ingin diwujudkan perusahaan dimasa depan dibandingkan dengan hasil kinerja sesungguhnya. Hasil perbandingan ini digunakan untuk melakukan evaluasi atas kinerja perusahaan (salman dan farid, 2016:56).
Menurut hery (2016:220) balanced scorecard adalah kumpulan ukuran kinerja yang terintergrasi yang diturunkan dari visi dan misi perusahaan.

\section{Empat Perspektif Balanced Scorecard Perspektif Keuangan (financial perspective)}

Kebanyakan bisnis didunia berorientasikan pada perspektif keuangan seperti orientasi pada laba bersih (net income). Arus kas dan memaksimalkan nilai pemegang saham (shareholpers value) (salman dan farid, 2016:62). Dalam balanced scorecard, sudut pandang keuangan tetap menjadi perhatian utama karna merupakan ikhtiar dari tindakan ekonomi yang telah diambil oleh perusahaan. Pengukuran kinerja keuangan menunjukkan apakah perencanaan, implementasi dan pelaksanaan strategi telah memberikan perbaikan yang mendasar bagi peningkatan laba perusahaan. Perspektif keuangan mengukur profitabilitas sebagai indikator seberapa baik perusahaan memuaskan pemilik dan pemegang saham. (hery, 2016:211)

Pada penelitian ini Perspektif keuangan diukur melalui rasio-rasio keuangan dari laporan keuangan sebagai berikut :

Rasio profitabilitas.

Rasio profitabilitas yang digunakan dalam penelitian ini ialah ROA (return on asset) menurut kasmir (2016:201) ROA digunakan untuk menunjukkan kemampuan perusahaan menghasilkan laba dengan menggunakan total asset yang dimiliki. Return on asset (ROA) menunjukkan kemampuan perusahaan dalam menghasilkan laba dari aktiva yang digunakan.

$R O A=\frac{\text { laba bersih setelah pajak }}{\text { total asset }} \times 100 \%$

Rasio Solvabilitas

Rasio solvabilitas yang digunakan dalam penelitian ini adalah debt to equality ratio menurut kasmir (2016:157) "debt to equality ratio merupakan rasio yang digunakan untuk menilai utang dengan ekuitas." Rasio ini berguna untuk mengetahui jumlah dana yang disediakan peminjam (kreditor) dengan pemilik perusahaan atau untuk mengetahui jumlah rupiah modal sendiri yang dijadikan untuk jaminan uang. Rasio ini juga memberikan petunjuk umum tentang kelayakan dan resiko keuangan perusahaan.

Debt to total equality ratio $=\frac{\text { total wtang }}{\text { ekwitas }} \times 100 \%$

Rasio Likuiditas

Rasio yang digunakan dalam menghitung tingkat likuiditas suatu perusahaan dalam penelitian ini adalah Rasio Lancar (current ratio), menurut kasmir (2016:134) "rasio lancar merupakan rasio untuk mengukur kemampuan perusahaan dalam membayar kewajiban jangka pendek atau utang yang segera jatuh tempo pada saat ditagih secara keseluruhan".

Current Ratio $=\frac{\text { asset lanear }}{\text { utang lanear }} \times 100 \%$

\section{Perspektif Pelanggan (customer perspective)}

Perspektif pelanggan adalah perspektif yang mengevaluasi dan mengukur kinerja yang berorientasi pada pelanggan 
sampai dimana tingkat kepuasan yang mereka peroleh. Hal ini dilakukan untuk mencapai target financial yang diharapkan. Suatu produk atau jasa akan semakin bernilai apabila kinerjanya semakin mendekati atau bahkan melebihi dari apa yang diharapkan perusahaan. Menurut sujarweni (2015:135-136) ada 3 hal yang digunakan sebagai bahan penilaian pelanggan yaitu tingkat kepuasan konsumen, seberapa besar penguasaan pangsa pasar perusahaan dan profitabilitas konsumen. Ini digunakan untuk mengukur seberapa besar.

\section{Perspektif Proses Internal Bisnis (internal businis perspective)}

Perusahaan akan menggembangkan tujuan dalam perspektif proses bisnis internal setelah menetapkan terlebih dahulu tujuan dan tolak ukur pada perspektif keuangan dan pelanggan. Melalui proses ini akan memungkinkan bagi perusahaan untuk mencari dan mempertahankan pelanggan dalam pasar yang telah ditargetkan (hery 2016:223). Perspektif proses bisnis internal adalah perspektif yang mengevaluasikan relevansi perancangan sistem peniliaian kinerja perusahaan yang mampu mengimplementasikan stretegi perusahaan dan membentuk suatu mekanisme proses bisnis internal yang baik. Tahapan dalam proses bisnis internal ini meliputi proses inovasi, proses operasi, dan proses penyimpangan produk atau jasa kepada pelanggan. (sujarweni,2015:136).

\section{Perspektif Pembelajaran Dan Pertumbuhan (learning and growth perspective)}

Perspektif pertumbuhan dan pembelajaran adalah perspektif yang menilai ukuran kinerja yang dapat mengarahkan perusahaan untuk melakukan perubahan agar dapat tetap berkembang dan menciptakan masa depan (sujarweni, 2015:136). Perspektif ini memberikan penekanan pada investasi insfrastuktur manusia, sistem informasi dan prosedur organisasi. (hery, 2016:224).

\section{METODE PENELITIAN}

Adapun metode penelitian yang digunakan adalah metode deskriptif, yaitu suatu rumusan masalah yang berkenaan dengan pertanyaan terhadap keberadaan variable mandiri, baik hanya pada suatu variable atau lebih (sugiyono, 2013:53). Jenis penelitian yang digunakan dalam penelitian ini adalah data kualitatif dan data kuantitatif.

Penelitian ini dilakukan pada perusahaan PT POS INDONESIA CABANG KUTACANE, beralamat Jalan Ahmad Yani-Kutacane no 91 Kode Pos 24651.

Teknik pengumpulan data dalam penelitian ini dengan melakukan wawancara yang melibatkan tanggapan para pegawai langsung mengenai variable yang diteliti. jawaban dari pertanyaan-pertanyaan dalam kuisioner diberi skor oleh peneliti atas tingkat kepuasan peneliti atas jawaban yang diberikan oleh responden.

Teknik analisis data dilakukan dengan melihat data-data fakta dari perusahaan berdasarkan masing-masing persepektif-perspektif yang ada didalam belenced scorecard, yaitu:

\section{Uji Validitas}

Menurut sugiyono (2015 : 2013) instrument yang valid berarti alat ukur yang digunakan untuk mendapatkan data (mengukur) itu valid, dengan kata lain instrument tersebut dapat digunakan untuk mengukur apa yang seharusnya diukur.

Pengujian validitas dalam penelitian ini dapat dilakukan dengan menggunakan SPSS dengan menelaah nilai pearson correlation. Data yang dinyatakan valid adalah jika pearson correlation $>0,3$. Setelah diperoleh bahwa pertanyaan-pertanyaan yang digunakan penelitian ini valid, maka selanjutnya pertanyaan yang dinyatakan valid diuji reliabilitasnya.

\section{Uji Reliabilitas}

Menurut sugiyono (2015: 203) instrument yang reliabilitas adalah instrument yang bila digunakan beberapa kali untuk mengukur objek yang sama, akan menghasilkan data yang sama. Reliabilitas dapat diartikan sebagai suatu karakteristik terkait dengan keakuratan, ketelitian dan kekonsistenan.

Penguji reliabiltas dalam penelitian ini dapat dilakukan dengan menggunakan program SPSS dengan menelaah nilai cronbach's alpha. Data yang ditanyakan realibilti adalah jika cronbach's alpha $>0,7$.

\section{PEMBAHASAN}

Penerapan Kinerja Dengan Pendekatan Balanced Scorecard Pada PT Pos Indonesia Cabang Kutacane meliputi perspektif keuangan, persepektif pelanggan, perspektif proses internal bisnis, perspektif pembelajaran dan pertumbuhan. Hasil perhitungan ke empat perspektif tersebut dapat dilihat di table berikut:

Tabel 1. Hasil Pengukuran Perspektif Keuangan

\begin{tabular}{|c|c|c|c|c|}
\hline \multirow{2}{*}{ Ukuran } & \multicolumn{3}{|c|}{ Tahun } & Rata- \\
& $\mathbf{2 0 1 6}$ & $\mathbf{2 0 1 7}$ & $\mathbf{2 0 1 8}$ & rata \\
\hline \multirow{2}{*}{ ROA } & 25,443 & 16,989 & 49,378 & 30,603 \\
& $\%$ & $\%$ & $\%$ & $\%$ \\
\hline \multirow{2}{*}{ DER } & 16,417 & 15,703 & 12,481 & 14,867 \\
& $\%$ & $\%$ & $\%$ & $\%$ \\
\hline CR & 34,856 & 27,694 & 11,516 & 25,688 \\
& $\%$ & $\%$ & $\%$ & $\%$ \\
\hline
\end{tabular}

Data diolah, 2019

Dari data diatas terlihat bahwa nilai ROA mengalami penurunan 8,454\% dari tahun 2016 sampai dengan 2017 jadi menggambarkan bahwa PT Pos mengalami peurunan terhadap hasil atas jumlah aktiva yang digunakan PT Pos Indonesia Cabang Kutacane. Kemudian dari tahun 2017 sampai dengan tahun 2018 mengalami peningkatan dimana PT Pos sudah dapat meningkatkan hasil atas jumlah aktiva yang digunakan PT Pos untuk mendapatkan laba. Dengan melihat hasil dari DER dari tahun 2016 sampai 2018 rasionya meningkat, tahun 2016 sampai 2017 naik 0,714 \% kemudian dari tahun 2017 sampai tahun 2018 naik lagi 3,22\% dimana artinya pendanaan utang semakin meningkat, maka akan dikhawatirkan perusahaan ini akan semakin sulit untuk memperoleh tambahan pinjaman. Dari hasil datatahun 2016 sampai tahun 2017 terjadi penurunan $7,162 \%$ dan dari tahun 2017 sampai 
2018 juga mengalami penurunan 16,178 \% artinya perusahaan ini mengalami kondisi yang tidak baik likuiditasnya karena akan menyebabkan terjadinya penurunan return saham.

\section{Mengukur Kinerja Perspektif Pelanggan}

Dalam pengukuran kinerja perspektif pelanggan dengan melalui tingkat kepuasan pelanggan terhadap kinerja PT Pos Indonesia Cabang Kutacane, setelah melakukan pengolahan data mentah dari kuisioner yang telah dibagi kepada pelanggan. Jumlah kuisioner yang dibagikan sebanyak 22 responden dimanakepuasan rata-rata jawaban dari 22 responden ialah 4,01 dimana dalam arti kata penilaiannya adalah baik artinya dalam proses pelayanan pelanggan PT Pos melakukan kinerja yang baik untuk kepuasan pelanggannya.

\section{Mengukur Kinerja Perspektif Proses Internal Bisnis}

Untuk melihat kinerja proses bisnis internal penelitian ini menggunakan dua bagian pengukuran yaitu Inovasi dan dengan hasil pertanyaan dari kuisioner yang disebarkan kepada karyawan. Kuisioner yang diolah berjumlah 22 responden atau karyawan yang bekerja dikantor pos agar dapat menilai bagaimana perkembangan karyawan atau sistem perkembangan pelayanan yang ada di PT Pos tersebut.

Tabel 2. Inovasi Produk Dan Jasa PT. Pos Indonesia Cabang Kutacane

\begin{tabular}{|c|c|c|c|}
\hline \multirow[b]{2}{*}{ INOVASI } & \multicolumn{3}{|c|}{ TAHUN } \\
\hline & $\begin{array}{c}201 \\
6\end{array}$ & $\begin{array}{c}201 \\
7\end{array}$ & $\begin{array}{c}201 \\
8\end{array}$ \\
\hline 1. Jasa Pickup Kiriman & & $\checkmark$ & $\sqrt{ }$ \\
\hline 2. Pos Order Number & & $\checkmark$ & $\sqrt{ }$ \\
\hline $\begin{array}{l}\text { 3. Layanan Pos Express } \\
\text { Sameday Delivery }\end{array}$ & & & $\checkmark$ \\
\hline 4. Asuransi Pos & & & $\checkmark$ \\
\hline $\begin{array}{l}\text { 5. Pembayaran Belanja Online } \\
\text { Dalam Negeri }\end{array}$ & $\checkmark$ & $\checkmark$ & $\checkmark$ \\
\hline 6. Rekening Giro Pensiunan & & & $\sqrt{ }$ \\
\hline 7. Wesel Cash To Account & & $\sqrt{2}$ & $\sqrt{ }$ \\
\hline $\begin{array}{l}\text { 8. Elektronik Prossesing On } \\
\text { Delivery }\end{array}$ & & & $\checkmark$ \\
\hline 9. Pengiriman Barang/Paket & 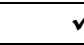 & $\checkmark$ & $\sqrt{ }$ \\
\hline
\end{tabular}

Sumber : PT Pos Indonesia Cabang Kutacane

Dari data tersebut dapat dilihat bahwa PT Pos setiap tahunnya selalu melakukan inovasi-inovasi terbaru terhadap produk-produk layanan jasanya agar pencapaian pelayanan PT Pos bisa melakukan yang terbaik baik agar menambah peningkatan di sector financial perusahaan.

Dalam pengukuran kuisioner perspektif proses internal bisnis dengan rata-rata 4,85 dimana dapat dikatakan bahwa perkembangan inovasi dan proses kerja di PT Pos Indonesia Cabang Kutacane baik bagi karyawan.

\section{Mengukur Kinerja Perspektif Pembelajaran dan Pertumbuhan}

Dalam mengukur perspektif pembelajaran dan pertumbahan penelitian ini melihat dari segi pertumbuhan sumber daya manusia karyawan dan pengembangan dan pengembangan system informasi penunjang kesuksesan PT Pos Indonesia Cabang Kutacane.

Tabel 3. Proses perkembangan karywan PT Pos Indonesia Cabang Kutacane

\begin{tabular}{|l|c|c|c|}
\hline \multicolumn{1}{|c|}{ Keterangan } & $\mathbf{2 0 1}$ & $\mathbf{2 0 1}$ & $\mathbf{2 0 1}$ \\
\hline 1.Pelatihan Keuangan & $\checkmark$ & $\checkmark$ & $\checkmark$ \\
\hline $\begin{array}{l}\text { 2.Pelatihan Pelayanan } \\
\text { Publik }\end{array}$ & $\checkmark$ & $\checkmark$ & $\checkmark$ \\
\hline 3.Pelatihan SDM & $\checkmark$ & $\checkmark$ & $\checkmark$ \\
\hline $\begin{array}{l}\text { 4.Pelatihan Unit Pelayanan } \\
\text { Luar }\end{array}$ & $\checkmark$ & $\checkmark$ & $\checkmark$ \\
\hline 5.Pelatihan Produk Pos & $\checkmark$ & $\checkmark$ & $\checkmark$ \\
\hline $\begin{array}{l}\text { 6.Pelatihan Proses Jalur } \\
\text { Kiriman }\end{array}$ & $\checkmark$ & $\checkmark$ & $\checkmark$ \\
\hline
\end{tabular}

Sumber : PT Pos Indonesia Cabang Kutacane

Dari data yang didapat PT pos Indonesia setiap tahunnya melakukan pelatihan agar SDM karyawan PT Pos melakukan pembelajaran yang terampil dan terlatih dibidang masing-masing.

Dalam pengukuran kuisioner perspektif pembelajaran dan pertumbuhan dengan rata-rata 4.76 artimya karyawan menanggapi PT Pos Indonesia Cabang Kutacane mampu memfasilitasi setiap bidang karyawan, kesejahteraan karyawan yang baik dan adanya pelatihan dan pendidikan tehadap karyawan agar memiliki SDM yang baik.

Tabel 4. Hasil Uji Validitas

\begin{tabular}{|c|c|c|c|c|c|}
\hline $\begin{array}{c}\mathbf{N} \\
\mathbf{0}\end{array}$ & $\begin{array}{l}\text { Pertanyaa } \\
\text { n }\end{array}$ & $\begin{array}{l}\text { Pearso } \\
n \\
\text { correla } \\
\text { tion } \\
(\mathrm{X} 1) \\
\end{array}$ & $\begin{array}{l}\text { Pearso } \\
n \\
\text { correla } \\
\text { tion } \\
(\mathrm{X} 2) \\
\end{array}$ & $\begin{array}{l}\text { Pearso } \\
n \\
\text { correla } \\
\text { tion } \\
(\mathrm{X} 3) \\
\end{array}$ & Ket. \\
\hline 1 & $\mathrm{X} 1, \mathrm{X} 2, \mathrm{X} 3$ & 0.405 & 0.512 & 0.523 & Valid \\
\hline 2 & $\mathrm{X} 1, \mathrm{X} 2, \mathrm{X} 3$ & 0.443 & 0.512 & 0.523 & Valid \\
\hline 3 & $\mathrm{X} 1, \mathrm{X} 2, \mathrm{X} 3$ & 0.794 & 0.397 & 0.576 & Valid \\
\hline 4 & $\mathrm{X} 1, \mathrm{X} 2, \mathrm{X} 3$ & 0.662 & 0.408 & 0.728 & Valid \\
\hline 5 & $\mathrm{X} 1, \mathrm{X} 2, \mathrm{X} 3$ & 0.756 & 0.762 & 0.724 & Valid \\
\hline 6 & $\mathrm{X} 1, \mathrm{X} 2, \mathrm{X} 3$ & 0.709 & 0.791 & 0.801 & Valid \\
\hline 7 & $\mathrm{X} 1, \mathrm{X} 2, \mathrm{X} 3$ & 0.490 & 0.512 & 0.560 & Valid \\
\hline 8 & $\mathrm{X} 1, \mathrm{X} 2, \mathrm{X} 3$ & 0.846 & 0.658 & 0.606 & Valid \\
\hline 9 & $\mathrm{X} 1, \mathrm{X} 2, \mathrm{X} 3$ & 0.548 & 0.472 & 0.446 & Valid \\
\hline 10 & $\mathrm{X} 1, \mathrm{X} 2, \mathrm{X} 3$ & 0.616 & 0.472 & 0.446 & Valid \\
\hline
\end{tabular}

Data diolah, 2019

Berdasarkan tabel diatas dapat dilihat bahwa nilai pearson correlation seluruh item pertanyaan pada perspektif pelanggan (X1), perspektif proses internal bisnis (X2), dan perspektif pertumbuhan dan pembelajaran (X3) adalah lebih besar dari 0.3. maka dapat disimpulkan 
bahwa seluruh item pertanyaan tersebut valid dan layak digunakan dalam penelitian.

\section{Tabel 5. Hasil Uji Reliabilitas}

\begin{tabular}{|c|c|c|}
\hline \multirow{2}{*}{ Ket. } & \multicolumn{2}{|c|}{ Reliability Statistics } \\
\cline { 2 - 3 } & Cronbach's Alpha & N of Items \\
\hline X1 & .816 & 10 \\
\hline X2 & .734 & 10 \\
\hline X3 & .836 & 10 \\
\hline
\end{tabular}

Data diolah, 2019

Berdasarkan tabel tersebut diatas, dapat dilihat bahwa nilai cronbach's alpha $=0.816>0.7$. maka dapat dinyatakan bahwa pertanyaan pada perspektif pelanggan (X1), perspektif proses internal bisnis (X2), dan perspektif pertumbuhan dan pembelajaran (X3) pada kuisoner ini adalah reliabel.

\section{KESIMPULAN DAN SARAN \\ Kesimpulan}

Berdasarkan hasil penelitian dan pembahasan yang dilakukan tentang Pengukuran Kinerja PT Pos Indonesia Cabang Kutacane dengan menggunakan pendekatan Balanced Scorecard, dapat disimpulkan:

1. Kinerja keuangan PT Pos Indonesia Cabang Kutacane menunjukkan kondisi yang tidak baik pada kurun waktu 2016 sampai 2018 yang ditandai dengan jumlah laba bersih setelah pajak, jumlah ekuitas, jumlah asset, dan jumlah utang yang dimiliki. Dilihat dari rasio yang digunakan (ROA, DER, dan CR) terhadap laporan keuangan PT Pos Indonesia Cabang Kutacane.

2. Kinerja pada persfektif pelanggan, PT. pos Indonesia Cabang kutacane telah melakukan berbagai hal untuk memberikan pelayanan yang baik kepada pelanggan. Pelanggan merasa puas dengan pelayanan selama ini dalam hal atribut pelayanan produk, citra dan hubungan karyawan terhadap pelanggan.

3. Kinerja pada persfektif proses bisnis internal yang meliputi inovasi dan observasi terhadap karyawan menunjukan hasil yang baik pada PT. pos Indonesia cabang kutacane PT. pos telah melakukan inovasi terhadap produk pelayanan biasa yang diberikan kepada masyarakat dan juga proses operasi dalam bentuk layanan jasa yang diberikan telah efisien dan efektif dalam sisi waktu pelayanan.

4. Kinerja pada persfektif pertumbuhan dan pelajaran dari hasil observasi kemampuan karyawan dan kepuasan karyawan menunjukan hasil yang baik pada. PT. Pos Indonesia Cabang Kutacane telah melakukan peningkatan karyawan melakukan berbagai bentuk pelatihan sehingga meningkatkan kinerja karyawan.

\section{Saran}

Berdasarkan penyajian dan analisis data sebelumnya maka dapat diberikan saran yang berhubungan dengan penelitian ini yaitu: PT. pos Indonesia cabang kutacane dari system pelayanan kepada pelanggan Sudah Baik hanya saja dari system pelayanan Fasilitas umum yang bisa ditingkatkan agar mencapai penilaian yang sangat baik. Untuk kondisi keuangan agar lebih ditingkatkan lagi supaya menjadi tunjangan kemajuan PT. pos kedepannya dan diharapkan penerapan pengukuran kinerja dengan pendekatan Balanced Scorecard ini agar dapat menjadi tinjauan pengukuran kinerja pada PT. pos Indonesia cabang kutacane.

\section{DAFTAR PUSTAKA}

Abdullah, Syukriy dan Abdul Halim. 2006. Studi Atas Belanja Modal Pada Anggaran Pemerintah Daerah Dalam Hubungannya Dengan Belanja Pemeliharaan Dan Sumber Pendapatan. Jurnal Akuntansi Pemerintah. Vol.2, No.2 Hal 17-32.

Alimudin, A (2017). analisis pencapaian strategi menggunakan balanced scorecard: Jurnal Pendidikan Ekonomi \& Bisnis, 5(2), 194-205. https://doi.org/10.21009/JPEB.005.2.6

Aloysius Christian Rico Aditama (2013). Analisis kinerja komprehensif dengan balanced scorecard pada PT. Kereta api indonesia. Universitas Diponegoro.

Anwar Prabu Mangkunegara (2016). Manajemen Sumber Daya Manusia Perusahaan. Bandung : Rosda

Arief dan Edy untung, (2016). Analisis Laporan Keuanagan. Jakarta: PT Grasindo

Fahmi, Irham (2016). Analisis laporan keuangan. Bandung : Alfabeta.

Farid, Salman (2016). Akuntansi Manajemen Alat Pengukur Dan Pengambil Keputusan Manajerial. Jakarta Barat : Indeks.

Ghozali, Imam (2016). Aplikasi Analisis Multivariete Dengan Program Ibm Spss (Edisi 8) Cetakan ke VII. Semarang: Badan Penerbit Universitas Diponegoro.

Harahap, sofyan syafri (2015). Analisi Kritis Atas Laporan Keuangan. Jakarta: raja grafindo persada.

Hery (2014). Analisis kinerja manajemen. Jakarta : grasindo.

Hery (2016). Balanced Scorecard For Business. Jakarta : Grasindo.

Hidayati Nuniek (2014). Pengukuran Kinerja Dengan Metode Balanced Scorecard. Universitas Muhammadiyah Surakarta. http://eprints.ums.ac.id/28871/17/naskah_Publika si_word.pdf.

Kasmir (2012). Analisis laporan keuangan. Jakarta : Raja Grafindo Persada. 
Marisa Lidya Rumintjp (2013). Penerapan balanced scorecard sebagai tolak ukur pengukuran kinerja di rsud noongan. Jurnal EMBA. Universitas Satu Ratulangi Manado. https://ejournal.unsrat.ac.id/index.php/emba/articl e/download/2289/1843.

Moehoriono (2012). Pengukuran Kinerja Berbasis Kompetensi. Jakarta : Raja Grafindo Perada.

Ni Putu Yessy Christina (2013). Penilaian kinerja pada pt. Adhi karya dengan pendekatan balanced scorcard. E-Jurnal Akuntansi Universitas Udayana5.3 (3013): 516529. https://ojs.unud.ac.id/index.php/Akuntansi/article /download/7418/5667.

Riswati, Mattalata (2018). Evaluasi kinerja, penilaian kinerja atas dasar prestasi kerja berorientasi kedepan : Celebes Media Perkasa.

Suwatno (2011). Manajemen Sumber Daya Manusia. Bandung : Alfabeta.

Sujarweni (2015). Metode Penelitian Bisnis Ekonomi. Yogyakarta: Pustaka Baru Press.

Sugiyono (2013). Metode penelitian pendidikan pendekatan kualitatif dan kuantitatif. Bandung: Alfabeta.

Veithzal Rivai (2015). Manajemen Kinerja Falsafah Teori \& Penerapannya Rajagrafindo Persada

https://repository.widyatama.ac.id/xmlui/bitstream/handle/ 123456789/6788/Bab\%202.pdf

Repository.Widyatama.ac.id

http://id.m.wikipedia.org/wiki/pos_indonesia 